\title{
Passivity Breakdown Studies of Chromium Steels with Progressive Addition of Chloride Ions*
}

\author{
By P. K. Mitra* and S. C. Sircar**
}

\begin{abstract}
Passivity breakdown characteristics of $\mathrm{Cr}$ steels have been studied by adding chloride ions progressively in sulfuric acid solutions. Effects of holding time at different potentials on the film growth have also been studied by adding a fixed quantity of chloride ions in sulfuric acid solution after a passive layer has been formed. Comparative study of corrosion kinetics has been made for different modes of experimentation. SEM studies have also been done to examine the nature of breakage of passive layers.
\end{abstract}

(Received October 1, 1986)

Keywords: passivity breakdown, progressive addition of chloride ions effect on, corrosion kinetics, critical amount of chloride ion addition

\section{Introduction}

It is generally believed that an oxide film is the reason for passivity and the breakdown of this protective film is the reason for passivity breakdown.

The main factors controlling the formation and growth of oxide layers are the potential of the metal and concentrations of metallic and hydroxyl ions ${ }^{(1)}$. It has been reported that the breakdown of the oxide layers are reported to depend on the concentration of chloride ions in the solution ${ }^{(2)(3)}$, and the higher the chloride ion concentration, the lower is the potential at which the breakdown of these oxides takes place $^{(4)-(6)}$.

In the present investigation it is found that once a passive layer is formed, the stability of oxide seems to increase with progressive addition of chloride ions. The breakdown of the passive layer is not only dependent upon potential but also upon the experimental conditions.

\section{Experimental}

Experiments were performed with $9.52 \% \mathrm{Cr}$

* Department of Metallurgical Engineering, Jadavpur University, Calcutta-32, India.

** Department of Metallurgical Engineering, Indian Institute of Technology, Kharagpur-721302, India. The work has been carried out at Dept. of Met. Eng., Jadavpur University. and $12.10 \% \mathrm{Cr}$ steels. In the first set of experiments a freshly prepared sample was mounted in a polarization cell set-up according to GS-72 and containing $0.5 \mathrm{kmol} / \mathrm{m}^{3} \mathrm{H}_{2} \mathrm{SO}_{4}$ solution. Fixed potential was applied and the steady current was measured. To this solution a weighed amount of $\mathrm{KCl}$ was added to make it $0.5 \mathrm{kmol} / \mathrm{m}^{3} \mathrm{H}_{2} \mathrm{SO}_{4}+1 \mathrm{molCl}^{-} / \mathrm{m}^{3}$ and again the steady current was noted. Further additions of chloride ions were made to measure the steady current. It was observed that for each addition of chloride ions it took about $600 \mathrm{~s}(10 \mathrm{~min})$ to reach the steady current state. In this manner chloride ions were added progressively to make the solution 1, 50, 100 and $200 \mathrm{molCl}^{-} / \mathrm{m}^{3}$, and for each stage steady current values were noted.

For the second set of experiments, like the previous set of experiments, a freshly prepared sample was mounted in a polarization cell containing $0.5 \mathrm{kmol} / \mathrm{m}^{3} \mathrm{H}_{2} \mathrm{SO}_{4}$ solution. A fixed potential was applied to passivate the sample and the variation of anodic current was noted as a function of time. After $1.2 \mathrm{ks}$ ( $20 \mathrm{~min}$ ) the weighed amount of $\mathrm{KCl}$ was added to this solution to make it $0.5 \mathrm{kmol} / \mathrm{m}^{3} \mathrm{H}_{2} \mathrm{SO}_{4}+1$ $\mathrm{mol} / \mathrm{m}^{3} \mathrm{Cl}$. Again the variation of current was noted as a function of time. In this manner similar experiments were done for both of the steels and kinetic data were recorded for the following solutions: $0.5 \mathrm{kmol} / \mathrm{m}^{3} \mathrm{H}_{2} \mathrm{SO}_{4}$ plus additions of $50 \mathrm{~mol} / \mathrm{m}^{3} \mathrm{Cl}^{-}, 100 \mathrm{~mol} / \mathrm{m}^{3} \mathrm{Cl}^{-}$, and $200 \mathrm{~mol} / \mathrm{m}^{3} \mathrm{Cl}^{-}$. For the first three solu- 
tions experiments were conducted at $0.90 \mathrm{~V}$ (vs SCE), whereas for the solution containing highest concentration of $\mathrm{Cl}^{-}$ions experiments were conducted at three different potentials.

Finally, experiments were done for $12.10 \%$ Cr Steel with $0.5 \mathrm{kmol} / \mathrm{m}^{3} \mathrm{H}_{2} \mathrm{SO}_{4}^{+} 100 \mathrm{~mol} /$ $\mathrm{m}^{3} \mathrm{Cl}^{-}$solution. In the same potentiostatic set up the current density was measured once by applying a fixed potential directly to the sample (mode A), and once for the same potential but reaching it by changing potential quasistationarily after starting from zero current potential (mode B). SEM photographs of pits were taken for the above two modes but care was taken so as to make the potential applied higher than the pitting potential.

\section{Results and Discussion}

Experiments were so designed that effect of progressive addition of $\mathrm{Cl}^{-}$ions on pitting characteristics of two $\mathrm{Cr}$ Steels could be studied.

From Figs. 1 and 2 it can be seen that when $\mathrm{Cl}^{-}$ions are added progressively in $0.5 \mathrm{kmol} /$ $\mathrm{m}^{3} \quad \mathrm{H}_{2} \mathrm{SO}_{4}$ solution just like potentiostatic diagram inflations are obtained which suggest

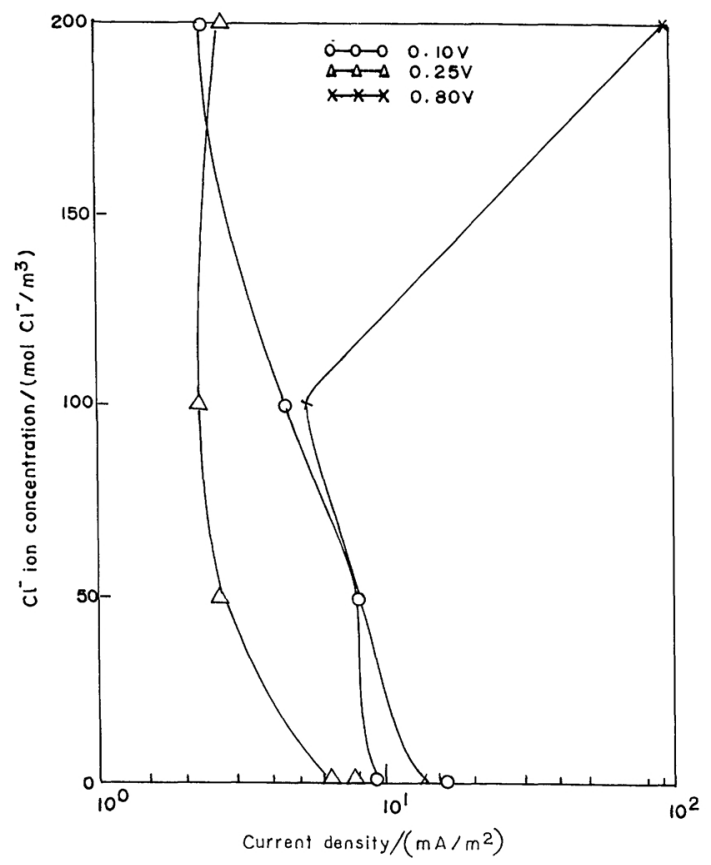

Fig. 1 Progressive addition of $\mathrm{Cl}^{-}$ions $9.52 \% \mathrm{Cr}$ steel.

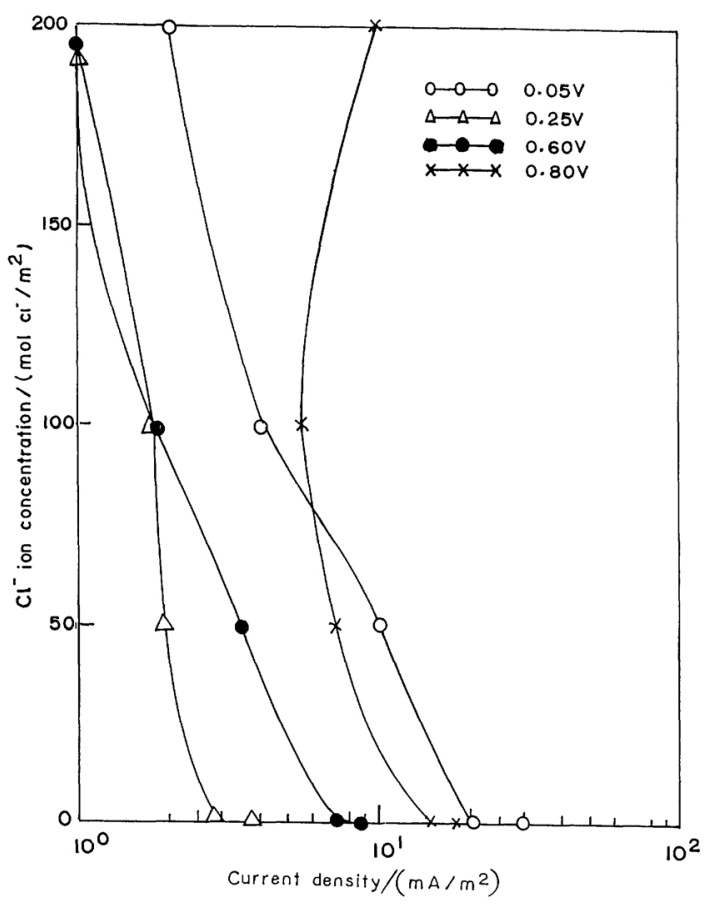

Fig. 2 Progressive addition of $\mathrm{Cl}^{-}$ions $12.10 \% \mathrm{Cr}$ steel.

that for a fixed potential a critical amount of $\mathrm{Cl}^{-}$ions may be found at which pitting starts. For example in Fig. 1 for applied potential $0.80 \mathrm{~V}$ (vs SCE), critical amount of $\mathrm{Cl}^{-}$ions is found to be $100 \mathrm{~mol} / \mathrm{m}^{3} \mathrm{Cl}^{-}$and in Fig. 2 for applied potential $0.80 \mathrm{~V}$ (vs SCE) critical amount of chloride ions is found to be slightly above $100 \mathrm{~mol} / \mathrm{m}^{3} \mathrm{Cl}^{-}$. Thus it seems that resistance against pitting increases as $\mathrm{Cl}^{-}$ions are added progressively in $0.5 \mathrm{kmol} / \mathrm{m}^{3} \mathrm{H}_{2} \mathrm{SO}_{4}$.

To find out whether this increase in resistance is due to the increase in holding time at a fixed potential, experiments were carried out to obtain Figs. 3-6. Figures 3 and 4 show that once the sample is passivated for $1 \mathrm{~mol} /$ $\mathrm{m}^{3}$ of $\mathrm{Cl}^{-}$ion addition there is a decrease in current density. For $50 \mathrm{~mol} / \mathrm{m}^{3}$ of $\mathrm{Cl}^{-}$addition the current density remains unchanged, while for $100 \mathrm{~mol} / \mathrm{m}^{3}$ of $\mathrm{Cl}^{-}$addition there is an increase in curent density. Figures 5 and 6 show that under similar experimental conditions for higher additions of $\mathrm{Cl}^{-}\left(200 \mathrm{~mol} / \mathrm{m}^{3}\right)$ the current density increases rapidly and the incubation time decreases with increasing potential. These results indicate that the holding time in- 


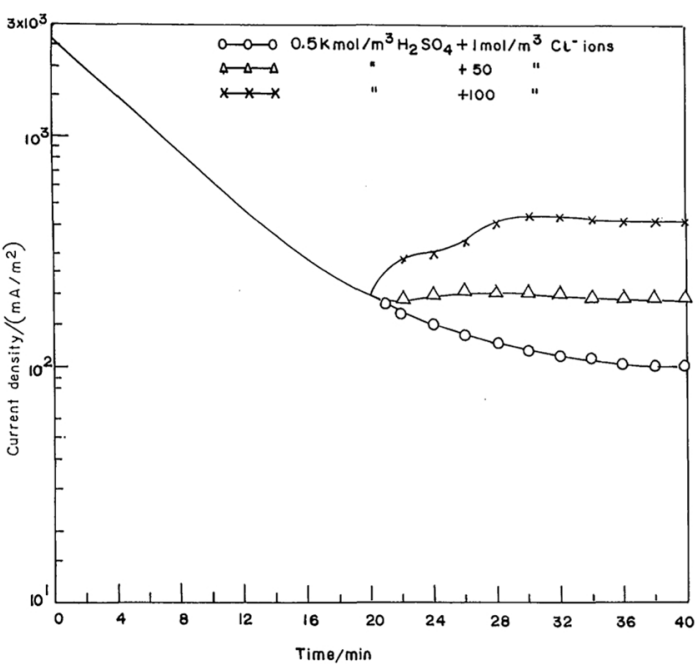

Fig. 3 Change in current density with time at a fixed potential of $0.90 \mathrm{~V}$ (vs SCE) for $9.52 \% \mathrm{Cr}$ steel and for different $\mathrm{Cl}^{-}$addition.

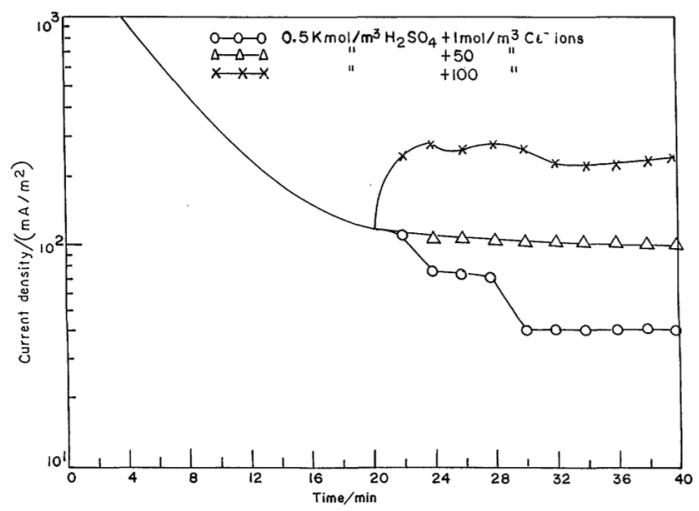

Fig. 4 Same as Fig. 3 except the sample is $12.10 \% \mathrm{Cr}$ steel.

Table 1 Steady currents at fixed potential when the potential is applied directly on the specimen (mode A) and when the potential is quasistationarily changed through passive region to trans-passivity (mode B). Sample $12.12 \% \mathrm{Cr}$ Steel, Medium $0.5 \mathrm{kmol} /$ $\mathrm{m}^{3} \mathrm{H}_{2} \mathrm{SO}_{4}+100 \mathrm{~mol} / \mathrm{m}^{3} \mathrm{Cl}^{-}$.

\begin{tabular}{lrr}
\hline \hline & \multicolumn{2}{c}{ Current in $\mathrm{mA} / \mathrm{m}^{2}$} \\
\cline { 2 - 3 } & $0.40 \mathrm{~V}$ & $0.60 \mathrm{~V}$ \\
\hline Mode A & 21230 & 57510 \\
Mode B & 4160 & 8710 \\
\hline \hline
\end{tabular}

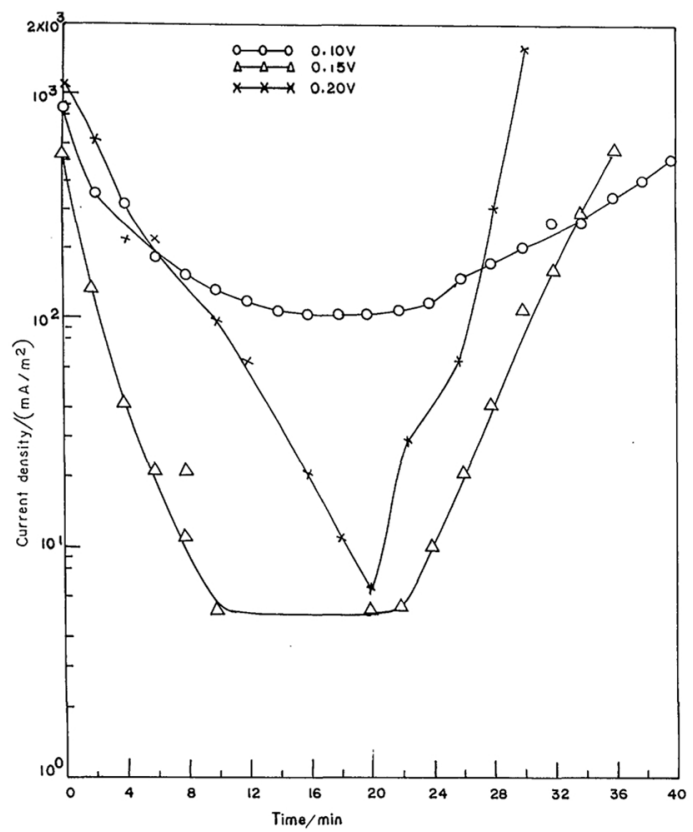

Fig. 5 Change in current density with time at different potentialy for $9.52 \% \mathrm{Cr}$ steel \& for $200 \mathrm{~mol} / \mathrm{m}^{3} \mathrm{Cl}^{-}$addition in $0.5 \mathrm{kmol} / \mathrm{m}^{3} \mathrm{H}_{2} \mathrm{SO}_{4}$ solution.

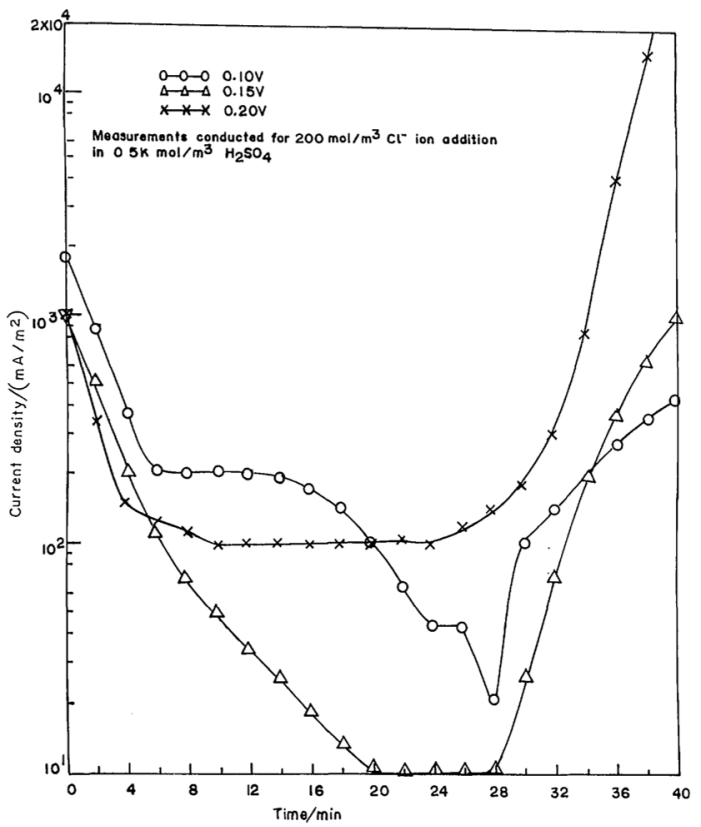

Fig. 6 Same as Fig. 5 except the sample is $12.10 \% \mathrm{Cr}$ steel. 


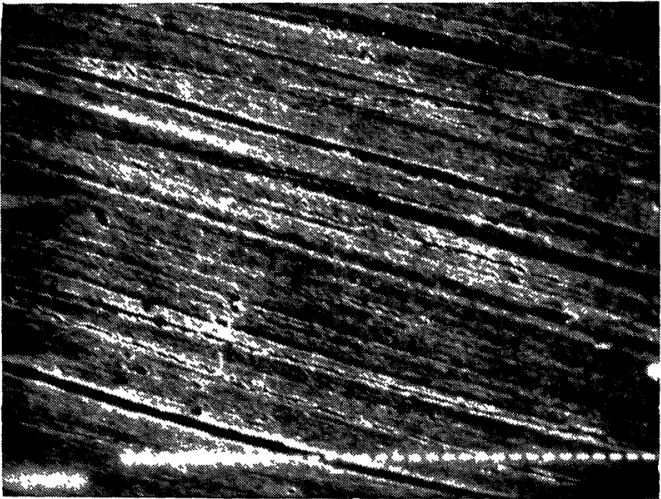

Fig. 7 Passive layer formed on the $9.52 \% \mathrm{Cr}$ steel $(\times 1600 \times 6 / 7)$.

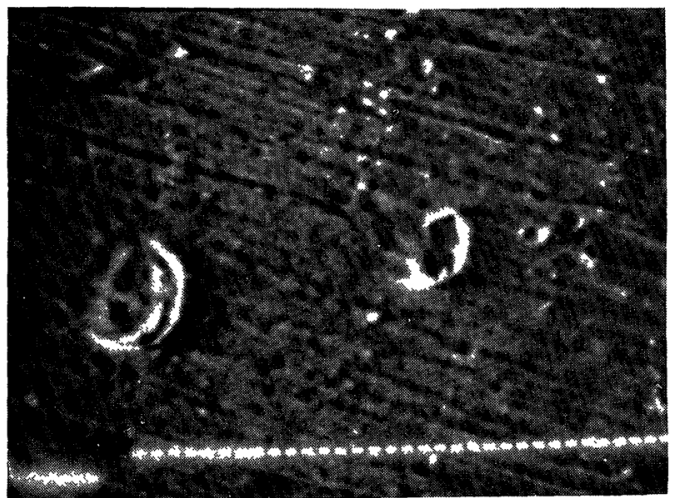

Fig. 8 Pits formed on $9.52 \% \mathrm{Cr}$ steel due to continuous polarization through trans passive region $(\times 1600 \times 6 / 7)$.

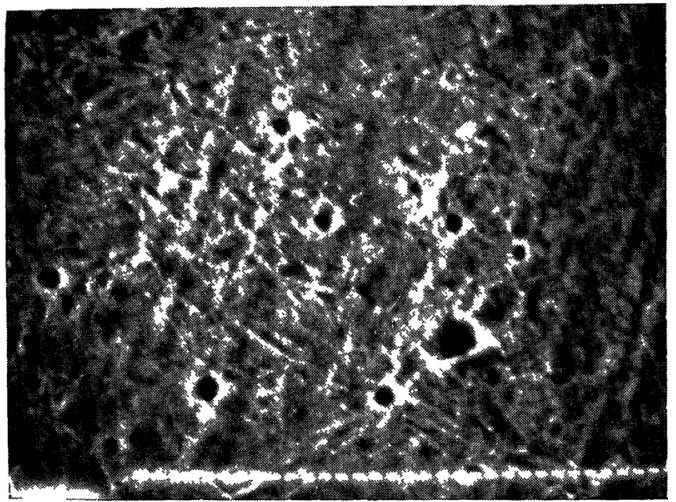

Fig. 9 Same as Fig. 8 except here sample is $12.10 \mathrm{Cr}$ steel rather than $9.52 \% \mathrm{Cr}$ steel $(\times 1600 \times 6 / 7)$.

creases the passive film thickness only when the solution concentration remains unchanged at a

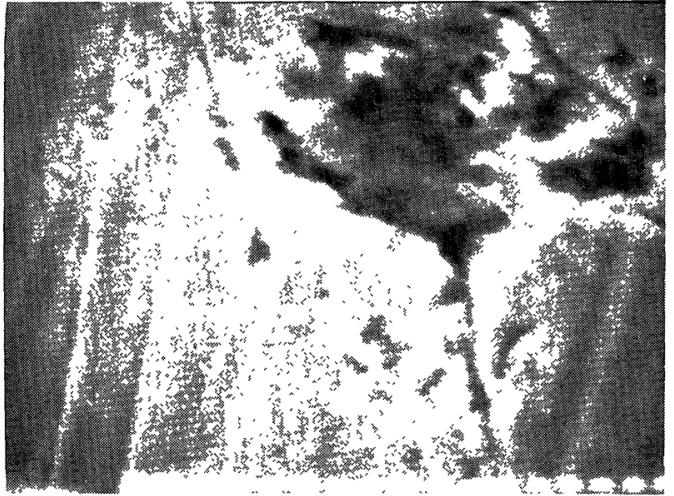

Fig. 10 Pits formed on $9.52 \% \mathrm{Cr}$ steel due to direct application of potential more than pitting potential $(\times 3200 \times 6 / 7)$.

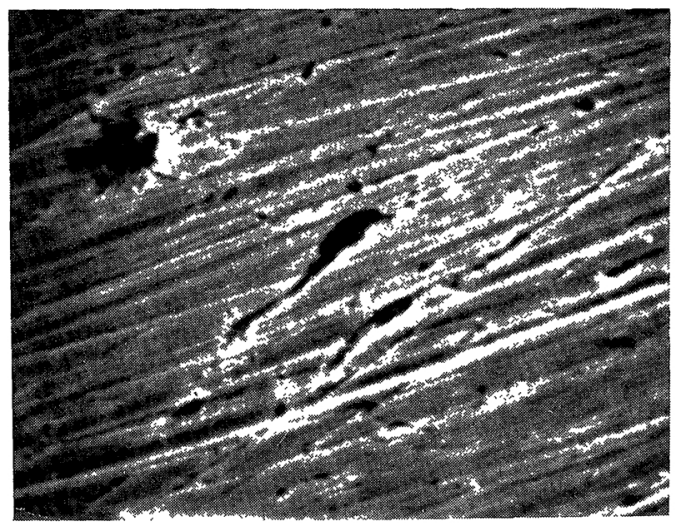

Fig. 11 Same as Fig. 10 except the sample is $12.10 \% \mathrm{Cr}$ steel. $(\times 6 / 7)$.

fixed potential.

Thus it may be said that the stability of passive oxide increases with the progressive addition of chloride ions.

From Fig. 2, the current density obtained for $0.60 \mathrm{~V}$ (vs SCE) at the $0.5 \mathrm{kmol} / \mathrm{m}^{3}$ $\mathrm{H}_{2} \mathrm{SO}_{4}+100 \mathrm{~mol} / \mathrm{m}^{3} \mathrm{Cl}^{-}$solution is $1.8 \mathrm{~mA} /$ $\mathrm{m}^{2}$. This value is considerably smaller than the values obtained for mode $A$ and mode $B$ as tabulated in Table 1. It is worthwhile to mention that the pitting potential of this sample in this medium is $0.325 \mathrm{~V}$ (vs SCE). From this comparison it becomes clear that with the progressive addition of $\mathrm{Cl}^{-}$ions pitting has not initiated even at $0.60 \mathrm{~V}$ (vs SCE).

It is seen that mode $\mathrm{A}$ gives a current density somewhat higher than mode B. There can be 
two reasons for this high current density for mode A. Either passive layer does not form at all, or it forms but its rate of destruction is much faster. SEM photographs of pits obtained for the two modes reveal that oxide layers do form in both cases. However, Figs. 10 and 11 reveal that the pit formation is due to some sort of tearing of the passive layer as if the breakdown is abrupt, whereas Figs. 8 and 9 show that pits formed by a gradual process suggesting some sort of nucleation and growth.

\section{Conclusion}

(1) After a passive layer is formed when chloride ions are added progressively, the stability of passive oxide increases.

(2) Rate of corrosion varies with experimental conditions, it being maximum when a potential is applied directly and minimum when chloride ions are added progressively.

(3) Nature of breakdown of passive layer also varies with experimental condition. For the quasistationary mode of change of potential, pitting is regular or gradual, whereas when a potential is applied directly breakdown of the passive layer is abrupt.

\section{REFERENCES}

(1) L. I. Antropov: Theoretical Electrochemistry, Mir Publishers, Moscow, (1972) p. 507.

(2) F. Fenwick: Ind. Eng. Chem., 27 (1935), 1095.

(3) H. J. Engell and N. D. Stolica: Arch. Eisenhüttenw., 30 (1959), 239.

(4) C. J. Semino and J. R. Galvale: Corros. Sci., 16 (1976), 297.

(5) A. D. Keitelman and J. R. Galvale: Corros. Sci., 22 (1983), 738.

(6) J. Brenet, T. Markovic and E. Altio: Werkst. Korros., 17 (1966), 119. 